\title{
A nova era do TIPS
}

\section{Francisco César Carnevale*}

O procedimento TIPS ("transjugular intrahepatic portosystemic shunt") representa um método terapêutico não-cirúrgico de redução da pressão portal nos pacientes cirróticos. Trata-se da confecção de um trajeto comunicando o território vascular hipertenso (veia porta) com outro de menor pressão (veia hepática-átrio direito), mediante interposição de uma estrutura tubular. Experimentalmente, o primeiro TIPS foi realizado em 1969 por Rösch e colaboradores. Naquele tempo, entretanto, o TIPS não podia ser empregado na prática clínica, porque não havia instrumentos nem materiais adequados para a aplicação da técnica e, principalmente, pela inexistência de estruturas que mantivessem a permeabilidade prolongada do trajeto realizado. 0 grande avanço desta técnica minimamente invasiva ocorreu há aproximadamente 20 anos, com a fabricação e aprimoramento de cateteres, balões de dilatação e, principalmente, pelos "stents" metálicos. Foi nessa época que Richter e colaboradores confeccionaram, com sucesso, o primeiro TIPS em humano.

Desde a sua introdução na prática clínica, o TIPS tem-se tornado cada vez mais conhecido e indicado como tratamento percutâneo para as complicações da hipertensão portal não controlada com medidas clínicas. No entanto, como em todos os do mínios da medicina, existem as correntes tradicionais contra essas evoluções tecnológicas. Esses "oponentes" alegam que ainda há a necessidade de resultados mais convincentes obtidos por meio de estudos randomizados, provando os benefícios do TIPS na manutenção do controle da hipertensão portal e, principalmente, no controle da sua permeabilidade tardia. Mas, todos se esquecem que o grande problema deste grupo de pacientes não é a hipertensão portal, mas o fígado deteriorado e incapaz de exercer suas funções fisiológicas. Resta, assim, o tão esperado e salvador transplante hepático!

Com o objetivo de lutar contra essas correntes, surgiram os tão esperados perpetuadores de permeabilidade do TIPS. O "stent" metálico revestido com politetrafluoretileno expandido (PTFE) tem-se mostrado ser o grande protagonista no avanço desse procedimento percutâneo. A sua utilização proporcionou maior tranqüilidade na punção e confecção do trajeto parenquimatoso intra-hepático, menor risco de complicações hemorrágicas e, principalmente, a "perpetuação da espécie", isto é, a permeabilidade e funcionamento adequado do TIPS.

* Chefe do Serviço de Radiologia Hoje em dia, quando os resultados da medicina baseada em evidências são aplicados, o procedimento TIPS ainda é submetido a discussões. Mas, todos aqueles que convivem com a experiência do método reconhecem que, quando corretamente indicado, os resultados são extremamente gratificantes no controle das complicações gravíssimas da hipertensão portal. Assim, deve-se salientar a importância da 
integração multidisciplinar entre gastroenterologistas, hepatologistas, equipe cirúrgica, intensivistas e radiologistas intervencionistas no diagnóstico, tratamento e controle dos pacientes submetidos a esta técnica. A única garantia de bons resultados em equipe é por intermédio da integração multidisciplinar e esforço individual de cada parceiro.

Após o sucesso do tratamento inicial do TIPS, resta o momento de preparar este paciente para a troca do órgão não funcionante. Define-se, assim, o tão chamado TIPS como uma "ponte" para o transplante hepático.

O TIPS tem um futuro brilhante. Com o desenvolvimento das novas gerações dos "stents" revestidos, maior será a vida útil do procedimento e, conseqüentemente, melhor a aceitação pela comunidade médica. As coisas boas não vêm facilmente e as dificuldades temporárias serão superadas com imaginação, criatividade, árduo estudo e trabal ho dos intervencionistas e com o essencial apoio das empresas médicas envolvidas nesses projetos. 